\title{
Simulation of the effect of low-cost companion animal clinics on the market for veterinary services
}

\author{
Roger B. Haston $\mathrm{PhD}$ \\ Sharon Pailler PhD
}

From The Institute LLC, Flagstaff, AZ 8600 I (Haston), and American Society for the Prevention of Cruelty to Animals, New York, NY IOI28 (Pailler).

Address correspondence to Dr. Haston (rhaston@ theinstituteforanimals.org).

\begin{abstract}
OBJECTIVE
To understand the market dynamics of companion animal veterinary services through the simulation of willingness to pay and willingness to wait as consumer behavior attributes.
\end{abstract}

\section{SAMPLE}

Numerical distributions for the willingness to pay and willingness to wait of simulated potential clients of companion animal clinics.

\section{PROCEDURES}

Simulations were run by use of numerical distributions to create demand curves and analyze market dynamics across 2 market segments (price sensitive and price insensitive) and different price dispersion between clinics.

\section{RESULTS}

The simulations suggested that the profit-maximizing price of a full-service clinic created a natural segmentation of the companion animal veterinary market, with a majority of clients coming from the price-insensitive segment. The simulation of 2 clinics (full-service and low-cost) with 2 market segments showed an increase in the overall market for veterinary services when a low-cost clinic was present. In addition, the lower the price charged at the low-cost clinic, the greater the profits for the full-service clinic.

\section{CONCLUSIONS AND CLINICAL RELEVANCE}

The presence of multiple prices for the same services, or price dispersion, in a market increases the overall market value and services more clients. Discouraging low-cost companion animal practices from entering the market decreases efficiency by leaving a population of pet owners unserved and ultimately reduces the overall market for veterinary services and the economic viability of veterinary practices.
$\mathrm{T}$ he veterinary medicine services field is large and growing, with an estimated market size of over $\$ 40$ billion in $2019 .{ }^{1}$ The number of veterinary visits per year has grown substantially from 78.6 million in 1987 to 123.3 million in $2016 .{ }^{2}$ The growth in this market can be attributed to a number of factors, including increases in pet ownership, ${ }^{2,3}$ life span of companion animals, ${ }^{4}$ and cost of veterinary care over the consumer price index. ${ }^{5}$

Despite this growth, there is a growing recognition that many animal owners within the US lack the resources to provide veterinary care for their pets. The American Society for the Prevention of Cruelty to Animals (ASPCA) estimates that over 20 million pets live in poverty, ${ }^{6}$ and the Access to Veterinary Care Coalition estimates there are approximately 29 million pets in households receiving Supplemental Nutrition Assistance Program benefits. ${ }^{7}$ The true number of pets that do not receive adequate veterinary care is unknown, although Pets for Life reports that $77 \%$ of the approximately 23 million pets currently living in underserved communities in the US have never been seen by a veterinarian and $87 \%$ are not spayed or neutered. ${ }^{8} \mathrm{~A}$ recent Access to Veterinary Care Coalition survey $^{7}$ found that $28 \%$ of pet owners experienced a barrier to veterinary care in the past 2 years, and $80 \%$ of those owners reported that cost was the primary barrier to care. Furthermore, a systematic literature review ${ }^{9}$ identified that the top 3 barriers to veterinary care in underserved communities were related to the cost of care.

The scale of this issue has fueled the growth of low-cost clinics, leading to contention within the veterinary field. Established private practice owners may perceive low-cost veterinary service providers as unfair competition. ${ }^{10-13}$ With grant funding and taxfree profits, low-cost, not-for-profit clinics can provide services at lower prices, leading some private practice owners to believe that low-cost clinics steal clients and fueling the perception that private practice veterinarians overcharge for their services..$^{11-13} \mathrm{~A}$ study $^{14}$ by Bayer Veterinary Care found that $20 \%$ of companion animal practice owners were concerned about competition from low-cost or limited-service clinics and perceived the relationship between private veterinarians and low-cost and nonprofit providers as strained. These perceptions have resulted in legal action that restricts low-cost clinics, including enactment of state laws preventing nonveterinarians from owning practices, limiting the services or areas low-cost clinics can operate, and even restricting grant funding for low-cost operations. ${ }^{13,15}$ 
While the impact of low-cost veterinary providers is assumed to be detrimental to established private practices, there has been little research in the veterinary literature that documents the impact of low-cost providers on the overall market for veterinary services. ${ }^{10}$ The absence of this important work has only fueled the perception that low-cost providers undermine the economic viability of many veterinary practices. The tendency has been to view the market as homogeneous rather than consisting of distinct groups or segments of buyers. Each of these segments responds differently to marketing and price, and this process is known as market segmentation. However, in many other industries, the concept and value of utilizing market segmentation to drive business performance is commonplace. ${ }^{16-18}$ Further, the presence of price dispersion and low-cost alternatives does not necessarily create unfair competition between higher- and lower-priced products. ${ }^{19-22}$

In the study reported here, we developed 2 simulated market models: one that demonstrated differences in demand for veterinary services across different market segments, and another that explored demand for veterinary services in low- and full-cost clinics across 2 different market segments. We believed that these simulated market models would provide important insights into the economic impact of lowcost providers on the market for veterinary services and the role of low-cost clinics in expanding access to care for pets in underserved households while providing a viable income stream for clinics.

\section{Materials and Methods}

The methodology used for the present study was Monte Carlo simulation developed on an open-source programming platform (Python 3.0; Python Software Foundation) utilizing normal and $\gamma$ distribution functions. This approach was used to incorporate the variability of probabilities and outcomes that more appropriately approximated real-life consumer behavior. Monte Carlo simulation builds a model of possible results by sampling a probability distribution for any variable that has inherent uncertainty (eg, willingness to pay [WTP]). The simulation then recalculates the results over and over, each time using a different set of random numbers between the minimum and maximum values for that variable. ${ }^{23}$ These types of models are common in economics, ${ }^{24}$ physics ${ }^{25} \mathrm{fi}$ nance,${ }^{26}$ climate,${ }^{27}$ and many other fields.

For the purposes of this study and to simplify the analysis, all of the modeling assumed a single product offering. All customers received the same service with no variation.

\section{Model I: a single veterinary clinic serving 2 market segments}

Willingness to pay is the maximum price a consumer accepts to pay for a product or service and encompasses a broad set of attributes, including a consumer's desire, knowledge, awareness, and ability to pay. ${ }^{28}$ Factors other than price that can affect the quantity of veterinary goods and services demanded include the quality, convenience, and friendliness of the veterinary practice. ${ }^{29}$ Although there is some relationship between income and WTP, ${ }^{30,31}$ the latter includes a broader set of attributes, from current market conditions to personal preferences. As such, people's WTP for veterinary services varies, and there are different market sectors of individuals who demand different levels of service at corresponding prices. ${ }^{10}$

The first simulated market model was created to estimate the impact of demand for a single product in a market with $>1$ market segment. In this model, a single clinic was assumed to provide a nonvarying service to a market with 2 different segments that each had different WTP distributions for the service.

The simulated market model was based on 2 populations of customers with different WTP attributes that represented price-insensitive (inelastic demand) and price-sensitive (elastic demand) market segments. The price-insensitive market segment reflected a pet-owning population who may have more disposable income or preferences for a specific service, compared with the price-sensitive market. The price-sensitive market segment reflected a pet-owning population who may have limited ability to pay for full-service veterinary care but demand quality veterinary care. The distributions of the 2 market segments (Supplementary Figure SI) were indicated by the following:

$$
\mathrm{WTP}_{\text {insens }} \varepsilon \mathrm{N}\left(\mu_{1}, \sigma_{1}\right)
$$

where $\mathrm{WTP}_{\text {insens }}$ is the WTP for a consumer in the price-insensitive segment and $\mathrm{N}$ is a normal probability distribution function with a mean $\left(\mu_{1}\right)$ of $\$ 120$ and $\mathrm{SD}\left(\mu_{1}\right)$ of $\$ 30$, and

$$
\text { WTP }_{\text {sens }} \varepsilon G(\alpha) X \beta
$$

where $\mathrm{WTP}_{\text {sens }}$ is the WTP for a consumer in the price-sensitive segment and $G$ is a $\gamma$ probability distribution where the shape parameter $(\alpha)$ equals 7 and the scale parameter $(\beta)$ equals 7.5 . These parameters were chosen to reflect a concentration of customers at lower WTP values and with far fewer customers with high WTP values.

The WTP mean of $\$ 120$ and SD of $\$ 30$ were chosen for the price-insensitive segment because these values centered the distribution for that segment around a typical cost for a routine clinic visit. $2,5,32,33$ A $\gamma$ distribution was chosen for the price-sensitive segment because it created a shallower slope of the demand curve, reflecting high price sensitivity and a concentration of customers at lower WTP values. The $\alpha$ and $\beta$ parameters were chosen to produce a distribution with a mean of $\$ 50$. A change in price caused a much larger change in demand for the pricesensitive segment than the price-insensitive segment. The WTP distributions for the segments were statistically different, yet they overlapped. When randomly sampled for the Monte Carlo simulation, they could 
be expected to produce different probabilistic outcomes. A variety of distributions was tested to evaluate the sensitivity of the model.

The simulation was run iterating through the price charged for the service ranging from $\$ 0$ to $\$ 250$, which spanned the majority of WTP values in the distributions. It was also assumed that potential clients were evenly split between the price-sensitive and price-insensitive segments. At each price level, the percentage of potential clients who had a WTP greater than the service price was calculated.

To assess the implications on a clinic's revenue and profits, it was assumed that each client visit had a $\$ 57$ variable cost that included labor and supplies; therefore, if the price was $\$ 120$, the gross profit would be $\$ 63$. The labor and variable costs for many clinics are in the range of $50 \%$ to $60 \%$ of revenue, ${ }^{34,35}$ and a typical price paid for a visit is between $\$ 110$ and $\$ 150,{ }^{2,3}$ Thus, assuming a reference price of $\$ 120$ for the clinic, the $\$ 57$ variable cost was in line with industry data. The model was run with the assumption that potential clients were evenly split between the price-sensitive and price-insensitive segments.

\section{Model 2: 2 veterinary clinics serving 2 market segments}

Model 2 was created to estimate the economic impact when 2 companion animal clinics operate in a market with a single service offering. One clinic was a low-cost clinic, and the other was a full-service clinic that charged a higher price. Two different market segments were defined with 2 key attributes: WTP and willingness to wait (WTW). The WTP for the price-sensitive and price-insensitive segments was as defined for model 1 . Wait time required to get a pet into the clinic was a function of number of clients in the hypothetical queue to get into the clinic; the scale was a relative time index and did not reflect actual time increments. Numerous economic studies document the influence of wait times on consumer behavior $^{36-39}$ and demonstrate that increased wait time increases the overall cost of a given product or service and reduces demand. ${ }^{40,41}$ As the time cost of a veterinary visit increases, fewer pet owners will be willing to wait to be seen by that veterinarian. The WTW is thus defined by the following relationship:

$$
\text { WTW } \left.=\mathrm{e}^{-([\mathrm{WTP} \times 1.5+20)} \times[\gamma \times \theta]\right)
$$

where $\gamma$ is a randomly sampled value between -0.35 and 0.35 and $\theta$ is a randomly sampled value between 1 and 2. The $\gamma$ and $\theta$ factors serve to create dispersion, where $\gamma$ is the dispersion around the trend line and $\theta$ is the variability for the range of dispersion, representing variation in consumer preferences. These factors create an increasing amount of dispersion at lower WTP values. Prior work demonstrates an inverse relationship between income and WTW for consumer products, ${ }^{42,43}$ professional services, ${ }^{44}$ and improved convenience for medical treatment. ${ }^{39,45}$
However, differences in individual preferences and the cost of waiting determine who will wait and for how long. ${ }^{46}$ Here, we assumed that variation in individual preferences and costs of waiting increase with decreasing income and WTP. The distributions for WTP and WTW for the 2 segments are shown (Supplementary Figure S2), as is the relationship between WTP and WTW (Supplementary Figure S3). The most basic interpretation of this relationship is that the less able or willing a person is to pay, the more willing that person is to wait or experience inconvenience.

Model 2 was constructed to reflect a dynamic interplay between the 2 clinic types (full service or low cost) and 2 market segments (price sensitive or price insensitive). An assumption was made that every potential client had perfect knowledge of the price and wait time present at each clinic. The pricing for the full-service clinic was fixed at $\$ 120$, while the lowcost clinic's price was referenced as a percentage of that full-service price. A number of simulations were run with the price offered by the low-cost clinic ranging from $0 \%$ to $100 \%$ of the full-service clinic price.

The model was run for 365 days, with customers and services for each day tracked within the model. The number of potential clients each day was sampled from a normal distribution with a mean of 75 clients and SD of 5; the market segment was assigned randomly with a $50 \%$ probability for each segment. The capacity of each clinic was set at 30 clients/d, which equated to approximately a 1 - to 1.5 -veterinarian practice using a typical number of patient visits per day. ${ }^{47}$ If the capacity of the clinic was exceeded for the day, the potential clients were added to the hypothetical waiting queue for the clinic. The size of the waiting queue was then used to calculate the wait time for that clinic. The WTW attribute for that hypothetical client was subsequently evaluated against the clinic wait time to determine whether the wait time was within the client's acceptable tolerance. If the wait time exceeded their tolerance and they had a WTP greater than that offered by the higher-cost clinic, by simulation the client was moved to the highercost clinic, and if the price of the higher-cost clinic exceeded their WTP, by simulation that client did not go to either clinic. A variety of WTP and WTW distributions were tested to evaluate the sensitivity of the model.

With the same set of assumptions as in model 1, the revenue and gross profit for both clinic types were calculated across the range of price differentials.

\section{Results}

\section{Model I}

The first simulation model showed that, at very low prices, both the price-sensitive and price-insensitive market segments hypothetically demanded a high quantity of services. As the price of that service increased, the percentage of price-sensitive poten- 
tial clients demanding services decreased faster than that of price-insensitive clients (Figure I). At a price of $\$ 100$, the clinic served almost exclusively clients from the price-insensitive segment.

The maximum revenue of the full-service clinic was achieved at a service price of $\$ 90$, while the maximum gross profit was achieved at $\$ 110$ (Figure 2 ). At the $\$ 90$ price, $93.1 \%$ of hypothetical clients were from the price-insensitive segment and only $6.9 \%$ were from the price-sensitive segment. At the $\$ 110$ price, $97.1 \%$ of clients were from the price-insensitive segment and only $2.9 \%$ were from the price-sensitive segment.

\section{Model 2}

The second simulation model showed that the quantity of demanded services increased with decreasing price. Accordingly, as demand increased at the low-cost clinic, the wait time to access services increased substantially (Figure 3). As wait times increased, more clients with a WTP greater than or equal to the price of the full-service clinic hypothetically experienced wait times greater than their WTW and thus chose the full-service clinic.

Three possible outcomes were included in the model: a person who was a full-service clinic client, a person who was a low-cost clinic client, and a person who was unserved by either clinic (Figure 4). Both the low-cost clinic and the full-service clinic had the highest percentage of clients when the price differential was the greatest (ie, when the low-cost clinic charged the lowest prices). As the price differential

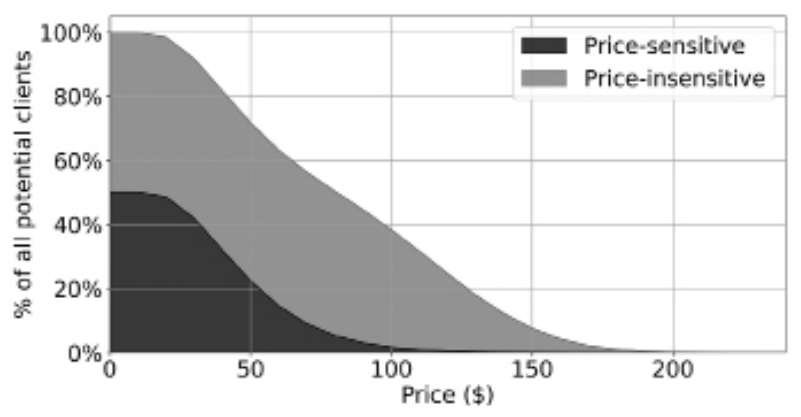

Figure I-Estimated percentage of the available market share by price for each segment.

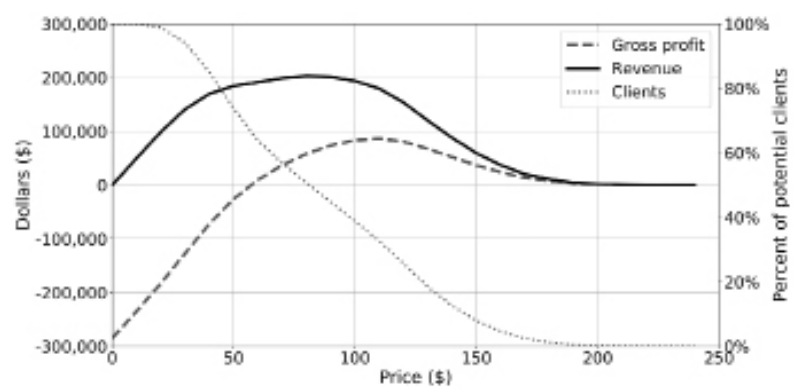

Figure 2-Estimated percentage of potential clients, total revenue, and gross profit for a given veterinary clinic at different prices for the same service. decreased and the low-cost clinic charged higher prices, the market accessed by both the low-cost clinic and the full-service clinic decreased; what increased dramatically was the number of people who were not served by either clinic. These unserved people represented a market inefficiency created when a potential client has a WTP below the market price but is nonzero or a WTW that cannot be satisfied.

Model 2 demonstrated varying demand at the 2 clinic types, depending on the price differential between them. Hypothetical use of the low-cost clinic ranged from $100 \%$ at the greatest price differential to $40 \%$ at equal price. The full-service clinic had a maximum utilization of $60 \%$ at the maximum price differential from the low-cost clinic, which dropped to approximately $37 \%$ when the prices at both clinic types were equal. Likewise, revenue at the 2 clinics varied on the basis of the price differential between them. As the price differential between the low-cost clinic and full-service clinic increased, the revenue for the full-service clinic increased. That is, the fullservice clinic experienced even greater revenue as the low-cost clinic charged lower prices. Revenue of the low-cost clinic initially increased as the differential decreased and reached a maximum of about $70 \%$ of the full-service clinic's price (Figure 5). A similar trend was seen regarding gross profit as well.

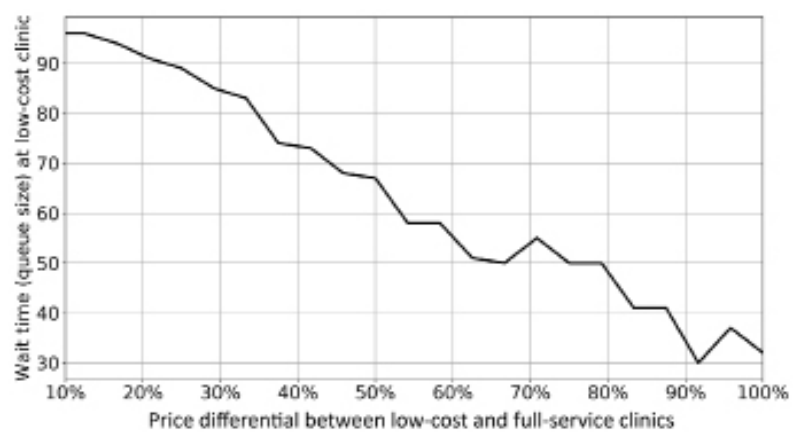

Figure 3-Hypothetical wait times at a low-cost veterinary clinic as a function of the percentage of price charged at a fullservice clinic $(\$ 120)$.

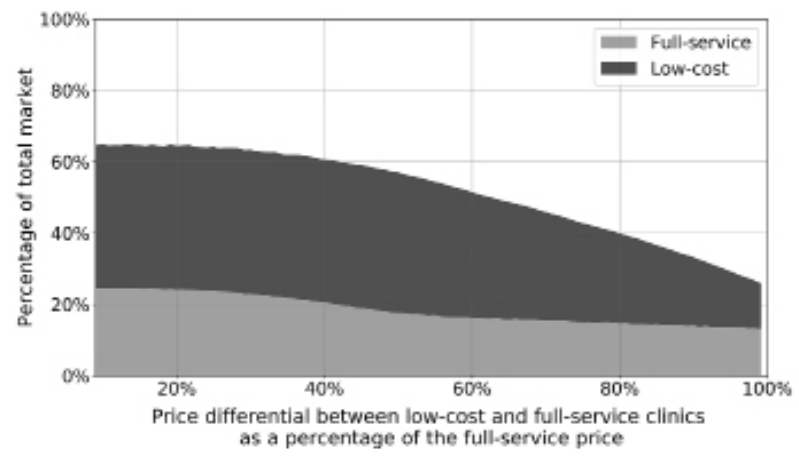

Figure 4-Estimated percentage of total market as a function of the price differential between a full-service clinic and a low-cost clinic. The white area represents the percentage of potential clients that went unserved by either clinic. The $x-$ axis is the percentage difference between the prices charged by the full-service clinic and the low-cost clinic. 

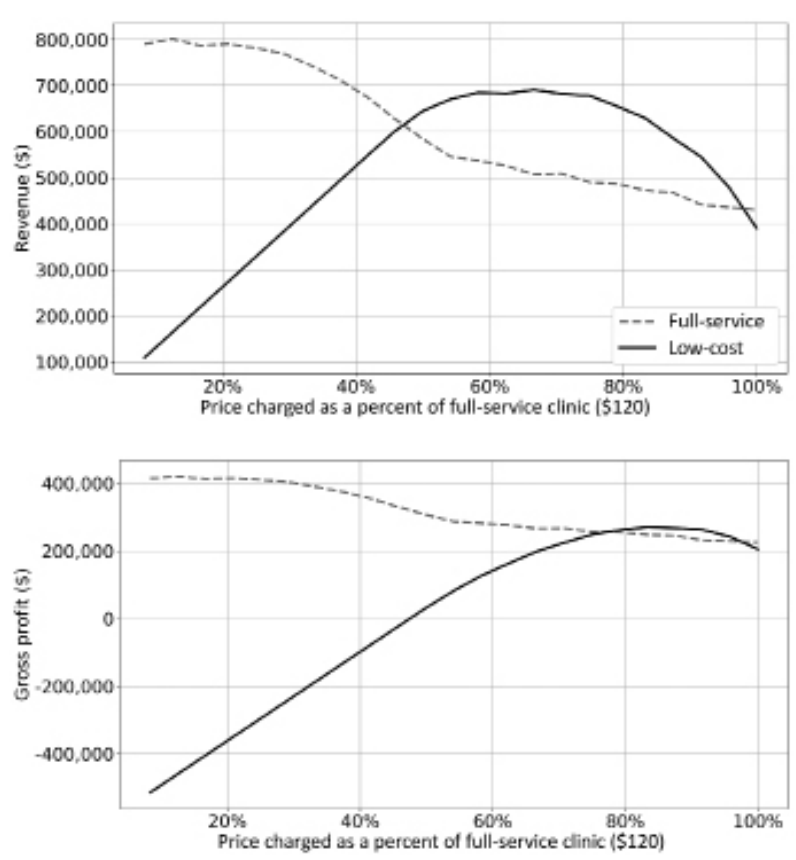

Figure 5-Estimated revenue and gross profit as a function of price differential between full-service and low-cost clinics. See Figure 4 for remainder of key.

\section{Both models}

A variety of distributions were tested to evaluate the sensitivity of the models. Models that incorporated greater dispersion around the mean, greater variability in WTW or WTP, or changes in the slope of the demand curve all yielded similar results. A key factor determining the percentage of customers from each segment was the degree and percentage of overlap between the 2 distributions; the greater the difference in the slope of the demand curves, the more the market segments were differentiated.

The aforementioned scenarios were run with the full-service clinic not necessarily operating at full capacity. In those scenarios, the full-service clinic's capacity usage ranged from $37 \%$, when there was no price differential between the full-service and lowcost clinic, to $61 \%$, when the price differential was the maximum. The low-cost clinic was able to run at full capacity up to a price differential of $47 \%$ and fell off to $37 \%$ utilization when there was no price differential.

To model the situation in which demand for services was greater than either clinic could service, the mean daily number of expected clients changed from a distribution with a mean of $75 / d$ to 1 with a mean of $200 /$ d. In this situation, the full-service clinic was at full capacity across the entire range of price differential. The price the low-cost clinic charged had no impact on revenue and gross profit of the full-service clinic. This made intuitive sense, as the number of customers with a WTP at or above the full-service clinic's price and who were unwilling to endure the significantly longer wait times at the low-cost clinic exceeded the capacity of the full-service clinic.

\section{Discussion}

A primary result of the present study was that, as simulated, the low-cost veterinary service provider served a different market segment than the fullservice provider; therefore, the low-cost provider did not steal clients from the full-service provider. Model 1 demonstrated that people in the price-sensitive market segment are not viable clients for full-service clinics; at the price that maximizes profit, there are very few potential clients from the price-sensitive segment who seek services from full-service clinics. The presence of market segments with different WTP creates a natural segmentation at the optimum price for the full-service clinic; therefore, clients who seek services at a low-cost clinic are not the same clients as those who take their pets to full-service clinics.

In Model 2, the interplay between WTP and WTW generated a more realistic consumer decision set in which a simulated potential client weighed their decision on the basis of more than 1 attribute: in this case, between cost and convenience. This model suggested that a greater price differential helps to target different market segments; the lower cost of services will draw a larger number of clients with lower WTP and higher WTW, which in turn drives those with lower WTW and higher WTP to the full-service clinic. Further, the full-service clinic gains more clients as the price differential increases and the WTW increases. There is customer discrimination through the inconvenience created by the wait time. Wait time acts as an effective customer selection mechanism, since the opportunity costs of waiting vary among people. For many people, the costs of waiting exceed the price at which the service can be bought; therefore, they will choose to pay a higher price in lieu of having to wait. ${ }^{46}$

In other industries, market segmentation has been shown to increase provision of goods and services by targeting different consumer bases. ${ }^{48-51}$ Market segmentation is also used in understanding the economics in health-care services. ${ }^{52-54}$ Although the concept of market segmentation has been widely studied in other industries, its explicit application to veterinary services has been limited. Some research on high-volume spay-neuter programs, however, provides evidence of market segmentation by demonstrating that low-cost clinics are not a substitute for full-service clinics because they target a different market segment.55,56 Pets receiving spay-neuter services at low-cost clinics tend to be from lower-income households and have never previously been seen by a veterinarian..$^{56,57}$ One study ${ }^{57}$ found that less than half of pet owners would have used a private practice rather than a low-cost spay-neuter clinic. These studies, coupled with the simulation results of the present study, highlight the opportunity to increase the number of pets receiving veterinary care by providing an array of veterinary service options.

Perhaps the most important results of these models were that the market for veterinary services was 
greater with both types of clinics, and as a result, many more pets were served. In this case, the percentage of the market accessed increased over $50 \%$ at the greatest level of price dispersion. This could translate into millions more pet owners being able to access veterinary care as well as the overall economic well-being of the industry being increased. Applications of modeling techniques that incorporate demographic, economic, and geographic data are needed to estimate the potential impact of low-cost veterinary clinics in a specific market.

The use of stochastic modeling to investigate the impact of competition and market segmentation in the veterinary services market is a powerful technique to provide understanding and insight. The simple, conceptual models of the present study provided insight into a narrow aspect of a more complex market. A simplistic view of competition is insufficient to account for the aspects that make up a person's choice to seek veterinary services. The results from this modeling highlighted the need for a broader view of those competitive forces beyond price and the need to account for different preferences and willingness and ability to pay. Our findings indicated that discouraging low-cost practices from entering the market decreases efficiency by leaving a population of pet owners unserved and ultimately reduces the overall market for veterinary services. If the goal is to increase the economic value of veterinary services and provide more companion animals with adequate health care, low-cost clinics should be welcome in the market.

\section{Acknowledgments}

The authors declare that there were no conflicts of interest.

The authors thank the ASPCA for generously providing funding and support to accomplish this work.

\section{References}

1. VeterinaryservicesintheUS-marketsize2004-2026. WorldIBIS Accessed December 31, 2020. https://www.ibisworld.com/ industry-statistics/market-size/veterinary-services-unitedstates/

2. AVMA Pet Ownership and Demographics Sourcebook: 2017-2018 edition. AVMA; 2018.

3. APPA National Pet Owners Survey 2017-2018. American Pet Products Association; 2018.

4 Banfield state of pet health 2013. Banfield Inc. Accessed December 31, 2020. https://www.scribd.com/document/ 140196171/Banfield-Pet-Hospital-State-of-Pet-Health-2013Report

5. 2017 AVMA Report on the Market for Veterinary Services AVMA; 2017.

6. ASPCA estimates number of pets living in poverty with their owners could exceed 24.4 million due to COVID-19 crisis ASPCA. Accessed December 18, 2020. https://www.aspca. org/about-us/press-releases/aspca-estimates-number-petsliving-poverty-their-owners-could-exceed-244

7. Access to Veterinary Care Coalition (AVCC). University of Tennessee. Accessed December 18, 2020. https://pphe.utk. edu/access-to-veterinary-care-coalition-avcc

8. Keeping Pets for Life. The Humane Society of the United States. Accessed December 18, 2020. https://www.humanesociety.org/issues/keeping-pets-life

9. LaVallee E, Mueller MK, McCobb E. A systematic review of the literature addressing veterinary care for underserved communities. J Appl Anim Welf Sci. 2017;20(4):381-394.

10. Dicks M. Supply and demand. AVMA. Accessed December 18, 2020. https://www.avma.org/resources/veterinary-economics/ economics/supply-and-demand

11. Fiala J. Veterinary nonprofits: unfair competitors or worthy charities? VIN News Service. Accessed Sep 12, 2021. https:// news.vin.com/default.aspx?pid $=210 \& I d=6256827 \&$ useobje cttypeid $=10 \&$ fromVINNEWSASPX $=1$

12. Larkin M. Lessons to be learned from relationships between nonprofits, veterinary clinics. J Am Vet Med Assoc. 2018;252(5):505.

13. Paul M. Divided we fall: nonprofit facilities and for-profit veterinary clinics seem constantly at odds. DVM360. Accessed December 31, 2020. https://www.dvm360.com/view/divided-we-fallnonprofit-facilities-and-profit-veterinary-clinics-seemconstantly-odds

14. Volk JO, Felsted KE, Thomas JG, Siren CW. Executive summary of the Bayer veterinary care usage study. J Am Vet Med Assoc. 2011;238(10):1275-1282.

15. Fiala J. Veterinary nonprofits: unfair competitors or worthy charities. VIN News Service. Accessed Sep 12, 2021. https:// news.vin.com/default.aspx?pid $=210 \& I d=6256827 \&$ useobje cttypeid $=10 \&$ fromVINNEWSASPX $=1$

16. Tynan AC, Drayton J. Market segmentation. J Mark Manag 1987;2(3):301-335

17. Smith WR. Product differentiation and market segmentation as alternative marketing strategies. J Mark. 1956;21(1):3-8.

18. Beane TP, Ennis DM. Market segmentation: a review. Eur J Mark. 1987;21(5):20-42

19. Narasimhan C. A price discrimination theory of coupons Mark Sci. 1984;3(2):128-147.

20. Shepard A. Price Discrimination in Retail Markets. Massachusetts Institute of Technology; 1989:64.

21. Regan TL. Generic entry, price competition, and market segmentation in the prescription drug market. Int J Ind Organ. 2008;26(4):930-948.

22. Blattberg RC, Wisniewski KJ. Price-induced patterns of competition. Mark Sci. 1989;8(4):291-309.

23. What is Monte Carlo Simulation? 2020. IBM. Accessed January 27, 2021. https://www.ibm.com/cloud/learn/monte-carlosimulation

24. Anderson PL. Business Economics and Finance with MATLAB, GIS, and Simulation Models. Chapman \& Hall/ CRC Press LLC; 2004:1-472.

25. Binder K, Heermann D, Roelofs L, et al. Monte Carlo simulation in statistical physics. Comput Phys. 1993;7(2):156-157.

26. Dagpunar JS. Simulation and Monte Carlo: With Applications in Finance and MCMC. Wiley; 2007:1-333.

27. Cubasch U, Santer BD, Hellbach A, et al. Monte Carlo climate change forecasts with a global coupled ocean-atmosphere model. Clim Dyn. 1994;10(1-2):1-19.

28. Le Gall-Ely M. Definition, measurement and determinants of the consumer's willingness to pay: a critical synthesis and directions for further research. Rech Appl Mark. 2009;24(2):91-113.

29. Brown BR. The dimensions of pet-owner loyalty and the relationship with communication, trust, commitment and perceived value. Vet Sci. 2018;5(4):95.

30. Punj G. The relationship between consumer characteristics and willingness to pay for general online content: implications for content providers considering subscription-based business models. Mark Lett. 2015;26(2):175-186.

31. Baumgärtner S, Drupp MA, Meya JN, Munz JM, Quaas MF. Income inequality and willingness to pay for environmental public goods. J Environ Econ Manag. 2017;85:35-61.

32. Food WP. How much will a vet visit cost? Wellness. Accessed January 21, 2021. https://www.wellnesspetfood.com/ourcommunity/wellness-blog/how-much-will-vet-visit-cost

33. Pet ownership costs guide for 2021. The Simple Dollar. Accessed January 21, 2021. https://www.thesimpledollar.com/ save-money/pet-cost-calculator/

34. How does your practice measure up? Live Oak Bank. Accessed December 31, 2020. https://www.liveoakbank.com/ 
wp-content/uploads/2014/05/14-LOB-Vet-White-Paper-Final. pdf

35. Dicks M, Maddux ML. The market for veterinary services: cracks in the foundation. VIN News Service. Accessed December 31, 2020. https://news.vin.com/default.aspx?pid= $210 \& I d=9063711$

36. Codina E, Marín Á, Montero L. A tool for the design of public transportation services. In: Proceedings of the International Conference on Management and Service Science (MASS 2012). World Academy of Science, Engineering and Technology; 2012:5.

37. Aryal K, Chaudhary P, Pandit S, Sharma G. Consumers' will ingness to pay for organic products: a case from Kathmandu Valley. J Agric Environ. 2009;10:15-26.

38. Wang N, Yan R. Research on consumers' use willingness and opinions of electric vehicle sharing: an empirical study in Shanghai. Sustainability. 2015;8(1):7.

39. Anderson RT, Camacho FT, Balkrishnan R. Willing to wait? The influence of patient wait time on satisfaction with primary care. BMC Health Serv Res. 2007;7:31.

40. Walsh RG, Miller NP, Gilliam LO. Congestion and willing ness to pay for expansion of skiing capacity. Land Econ. 1983;59(2):195-210

41. Maddison DJ, Terry F. Valuing congestion costs in the British Museum. Oxf Econ Pap. 2003;55(1):173-190.

42. Zanghieri P, Rossini G. What drives price differentials of consumables in Europe? Size? Affluence? Or both? Open Econ Rev. 2008;19(1):121-134.

43. Goebel P, Moeller S, Pibernik R. Paying for convenience: at tractiveness and revenue potential of time-based delivery services. Int J Phys Distrib Logist Manag. 2012;42(6):584-606.

44. Bechwati NN. Willingness to pay for professional services. $J$ Prod Brand Manag. 2011;20(1):75-83.

45. Gavirneni S, Kulkarni V. Concierge medicine: applying rational economics to health care queuing. Cornell Hosp $Q$. 2014;55(3):314-325

46. Nichols D, Smolensky E, Tideman TN. Discrimination by waiting time in merit goods. Am Econ Rev. 1971;61(3):312323.

47. Q\&A: research before you build a veterinary practice.
DVM360. Accessed December 31, 2020. https://www. dvm360.com/view/qa-research-you-build-veterinary-practice

48. Thach EC, Olsen JE. Market segment analysis to target young adult wine drinkers. Agribusiness. 2006;22(3):307322.

49. Epetimehin FM. Market segmentation: a tool for improving customer satisfaction and retention in insurance service delivery. J Emerg Trends Econ Manag Sci. 2011;2(1):62-67.

50. Funk DC. Consumer-based marketing: the use of micro-segmentation strategies for understanding sport consumption. Int J Sports Mark Sponsorsbip. 2002;4(3):231-256.

51. Ahani A, Nilashi M, Ibrahim O, Sanzogni L, Weaven S. Market segmentation and travel choice prediction in spa hotels through TripAdvisor's online reviews. Int J Hospit Manag. 2019;80:52-77.

52. Vuik SI, Mayer EK, Darzi A. Patient segmentation analysis offers significant benefits for integrated care and support. Health Aff (Millwood). 2016;35(5):769-775.

53. Jha S, Baker T. The economics of health insurance. J Am Coll Radiol. 2012;9(12):866-870.

54. Ross CK, Steward CA, Sinacore JM. The importance of patient preferences in the measurement of health care satisfaction. Med Care. 1993;31(12):1138-1149.

55. Frank JM, Carlisle-Frank PL. Analysis of programs to reduce overpopulation of companion animals: do adoption and low-cost spay/neuter programs merely cause substitution of sources? Ecol Econ. 2007;62(3-4):740-746.

56. White SC, Scarlett JM, Levy JK. Characteristics of clients and animals served by high-volume, stationary, nonprofit spayneuter clinics. J Am Vet Med Assoc. 2018;253(6):737-745.

57. Benka VA, McCobb E. Characteristics of cats sterilized through a subsidized, reduced-cost spay-neuter program in Massachusetts and of owners who had cats sterilized through this program. J Am Vet Med Assoc. 2016;249(5):490-498

\section{Supplementary Materials}

Supplementary materials are posted online at the journal website: avmajournals.avma.org. 